\section{Climital a dotes:}

\section{MEDICAL, SURGICAL, OBSTETRICAL, AND THERAPEUTICAL.}

\section{A CASE OF \\ PYOCELE OF THE FRONTAL SINUS.}

By J. A. GIBb, M.D. Aberd.,

HON. SURAEON, KENT COUNTT HOSPITAL FOR DISEASES OF EYT, EAR, NOSE, AND THROAT, MAIDSTONE.

THE following case is interesting, although the recent Hunterian Lecture by Mr. W. J. Howarth has shown me that the condition is not so uncommon as I had formerly supposed.

On May 18th I was asked by Mr. G. Potts, ophthalmic surgeon to the hospital, to examine a patient, aged 57, for frontal sinusitis. She had a slight swelling at the inner canthus of the left eye, and complained of some " pricking in the left eye," but not of headache or other subjective symptom. The swelling was firm and could not be pressed away. Intranasal examination showed no discharge on and no enlargement of turbinate bones. Post-nasal space - and no enlargement of turbinate bones. Post-nasal space sinuses clear and of about normal size; maxillary antrum also clear ; no history of a blow. My report was : frontal, ethmoid, and maxillary sinuses unaffected.

Three months after this the patient was admitted into hospital with a compressible swelling on her left fronta sinus. The house surgeon, Dr. K. Reed Hill, needled it and got pus. There were no subjective symptoms such as headache, and the temperature was negligible. The eyeball was pushed downwards and outwards with swelling of the soft tissues of the upper eyelid and inner angle of orbit.

Operation.- I operated as soon as the patient could be got ready, making an incision along the eyebrow ; there was an immediate gush of odourless, reddish muco-pus. A gloved finger was inserted into the cavity, which was felt to be unusually large. I therefore made a further incision at right angles to the original at its inner angle, going well up the forehead; the flap was turned upwards and the cavity swabbed dry and all bleeding arrested.

The following was then made clear: The anterior wall of the sinus, with the exception of a thin pliable piece of bone adherent to the flap, was absorbed. The floor, except for a small plate of bone over the orbit, the posterior wall, and the septum between the two sinuses were also absorbed, so that the right frontal sinus could easily be explored; portions of dura mater were missing, red and inflamed brain substance being exposed. A probe could be passed on either side into the nose; the posterior ethmoid cells were absorbed. The fronto-nasal duct could not be made out; the probe could be passed down to the loop of the post-nasal space, the mucoperiosteum everywhere being intact, except where the orbital plate had been absorbed; here the probe passed into the cheek. The sagittal sinus was intact, but the whole left frontal lobe was completely exposed and could, if it had been desirable, have been raised and its under surface explored.

The wound was sutured with the exception of its outer and inner angle, which were drained. Recovery was gradual and the temperature and pulse negligible throughout until at the end of three weeks a pocket of pus, quite different from the original infection, formed under the scalp at the inner angle of the original incision and extended down to the cheek. This was opened, gently scraped, and swabbed out with hypochlorite solution.

The patient is now quite well. I deemed it inadvisable to open up any communication with the nasal cavities, as I felt that the cavity would become filled with fibrous tissue, the condition, in my opinion being one of mucocele of the frontal sinus which had become infected.

Abstract of Ophthalmological Report.

Patient attended hospital on May 14th complaining of slight discomfort behind the left eye. On examination Mr. Potts found vision R.E.6/6, L.E. 6/12 ; small swelling felt below left supra-orbital notch; slight proptosis and displacement of eye downwards and outwards ; no diplopia. Fundus normal. On re-examination four months later the eye had returned practically to its normal position. The proptosis had disappeared, but there was very slight displace-
ment of the eye downwards, the level of the left pupil being about $2 \mathrm{~mm}$. below that of the right. Fundus, optic dise and media normal. On testing for heterophoria the left image was found to be situated above and to the right of the right image, but they were approximately fused by a $12^{\circ}$ prism base upwards and inwards. The extrinsic muscles appeared not to have been affected, as there was no limitation of movement of the eye. The fields showed no contraction, nor were any scotomata to be made out with either white or colours.

\section{A CASE OF SYRINGOMYELIA.}

\section{By W. Sibbald Robertson, M.D. Edin.}

Syringomyelia, a rare disease in this country, is usually and correctly described as slowly progressive and incurable, but remissions are not uncommon; it may be of interest to give some account of a case in which apparent arrest of the malady and disappearance of the symptoms have proved more nearly complete than can usually be hoped for or expected.

The patient, R. J., first came under my care as long ago as 1907 . She was a single woman, aged 26 , the youngest of a family of 16 . Having in mind the accepted view ot the atiology of the disease, it may not be irrelevant to mention that her twin sister has been a normally healthy woman all her life, presenting no sign of developmental defect. The family history is good; the patient herself gave no history of nervous or venereal disease or serious illness of any kind. She cannot be described as bright mentally. In 1905 she developed a whitlow, which became so severe that amputation of the finger was ultimately performed. During the next two years she was treated in hospital on several occasions for severe-but painless-whitlows; more than once she burnt or scalded herself ; in 1907 the terminal phalanges of a thumb and two fingers were painlessly removed for some septic condition. During this time, also the patient complained of a gradually increasing weaknes in her hands and arms, but the true causation of her local troubles does not seem to have been recognised.

In June, 1907, examination showed irregular distributed patches on her arms, hands, feet, chest, face, and uppe part of her lower limbs, where sensations to pain and to hea and cold were completely absent, although tactile sensation was unaffected (dissociated anæsthesia). There was marked muscular atrophy of the thenar and hypothenar eminences, with fibrillary muscular tremors and diminution in the faradic response; there was also extreme left-sided hemi atrophy of the tongue. The patient complained of frequen shooting pains, sometimes of a girdle character round the trunk, but oftenest of an anginous trpe, running from the pracordia up the neck and down the arm; the hands were blue and cold, and the patient suffered from-or at least developed-numerous chilblains; her nails were cracked and furrowed, and she was very subject to fainting fits and had constantly a rapid, low tension pulse. Her knee-jerks were increased, and she had difficulty in walking. The plantar reflexes were normal. Her speech was hesitating and staccato, and she was subject to dribbling of saliva from the mouth. The stereognostic sense was apparently normal and the pupils, spine, and joints were unaffected.

Treatment. - The treatment adopted was purely symptomalic; regular courses of Easton's syrup and of tonics containing nux vomica, strychnine, and iron and the like were given ; the pain was relieved with phenacetin, antipyrin bromides, \&c., and (when the attacks were exceptionally severe) morphia; regular action of the bowels was secured and strophanthus was given to counteract the circulatory weakness.

At first the progress of the case was as expected. The general condition and all symptoms became gradually worse, and during the whole of 1908 and 1909 she was altogether bedridden. In 1910 improvement set in, her nails (which she had had no occasion to cut for years) began to grow. her tongue increased in size, her speech improved, walking became possible, and her heart and circulation gradually recovered tone. Since January, 1911, she has done all her housework unaided, and has had no further whitlows or traumata of any kind. 1

Examination in September, 1921, showed her speech to be normal and her gait almost so; the knee-jerks remain slightly exaggerated and there are still some patches of dissociated anzesthesia on her soles. But in all other respects she appears healthy, able to live a fairly busy and useful life.

The diagnosis of the case presented but little difficulty; but it was more than once missed by I The patient was shown at a meeting of the B.M.A. at
Scarborough in 1911. 
observers who concentrated their attention on local lesions. Of much more interest is the unlooked-for amelioration in all the symptoms and the long period of time over which the improvement has been maintained. Remissions for a dozen years or longer have been reported, but I have failed to trace any instance in which a case so apparently desperate achieved what may at present pass tor almost complete recovery and natural arrest of the disease.

West Ayton, Yorks.

\section{PARA-URETHRAL GONORRHEA.}

By F. Chamberlain, M.R.C.S., L.R.C.P. Lond., HOUSE SURGEON TO THE LONDON LOCK HOSPITAL.

A para- or accessory urethra is a small blind canal lying somewhere between the meatus urinarius and the penile-scrotal junction in the long axis of the penis. The canal opens at the distal end but is closed at the proximal end and does not communicate with the urethra proper. The lining is of epithelial cells supported by connective tissue, indistinguishable in form and arrangement from those lining the urethra, a small bore urethra in effect. In most cases the urethra is of narrow calibre and one gains the impression that the condition is due to a developmental error whereby a portion of the urethral track is cut off from the main urethra.

In certain cases these canals may become infected with gonococci, the urethra proper escaping. hazard the theory that the cause is largely mechanical. In Case 1 the extreme phimosis must to some extent have protected the meatus urinarius, while the opening of the canal on the under surface of the prepuce would bear the brunt of the onslaught during coitus. In Case 2 the three openings were close together, but the meatus was very narrow, hardly admitting an $11 \mathrm{~F}$. bougie, and the lips were indrawn, presenting the resistant skin surface of the penis instead of the delicate lining of the urethra. Distension of the glans during erection rendered the para-urethral openings more prominent.

CASE 1.- Aged 23, no previous venerea! disease. Marked phimosis; had never been able to retract foreskin. Narrow lueatus; an ovoid swelling, 12 by $6 \mathrm{~mm}$., on the under surface of the penis with pus exuding from four openings. A fine probe passed through the distal opening demonstrated a canal $3 \mathrm{~cm}$. in length lving superficially in the raphé. Pus container gonococci. Urine was limpid and contained no contain

Trealment.-The canal was dissected out and the edges sutured. Healed by first intention. Three months later a faint scar was discernible; there had been no signs of urethral gonorrhœea.

CASE 2.-Aged 23, no previous venereal disease. Three days after coitus noticed a "boil" on the glans. This was treated with foments and later with various ointments till another boil arose and the end of the penis became impetiginised. On examination a pocket $3 \mathrm{~mm}$. in depth was found, and proximal to this a canal $3 \frac{1}{2} \mathrm{~cm}$. in length, starting $6 \mathrm{~mm}$. from the meatus and passing from the glans, through the frenal fold, and on to the prepuce to the skinmucus junction.

Treatment.-The septum between the pocket and the canal was perforated and the whole track laid open with a pair of iridectomy scissors and packed with acriflavine gauze; the wound healed, leaving a ribbon-like track. Two months later the track was hardly distinguishable from the rest of the penis. 'There had been no signs of urethral gonorrhoea; gonococci were found in the original discharge from the canal.

CASE 3.-Mr. J. E. R. McDonagh has given me permission to include a case in which the track extended almost the whole length of the raphé and the pent-up pus had made its way to the surface by several openings. Gonococci were found in the pus; no signs of urethritis then or since. The track was dissected out and the wound sewn up. No trouble since.

It is important to recognise that these ducts can be infected without any signs of "gonorrhoea," as, by the time the patient has maltreated his penis with irritating ointments to cure his "sore," the original lesion will be quite unrecognisable, and there is no urethral discharge to give one a lead. Hot dressings and ointments will then be of no avail.

I am indebted to Mr. MeDonagh and Mr. Johnston Abraham for permission to publish these cases.

\section{A FATAL CASE OF \\ DELAYED NEO-SALVARSAN POISONING.}

BY D. R. C. Shepherd, M.B., M.R.C.P. Lond., TEMIP. CAPTAIN, R.A.M.C.; MEDICAI. SPECIALIST, ALDERSHOT COMMAND.

DEATH due to the means of cure of syphilis is by no means rare, but in the case here recorded death occurred 111 days after the last of seven injections of neo-salvarsan.

J. G., a soldier, aged 21 , commenced treatment on Sept. 9th, 1920, after the Spirochceta pallida had been found in his primary sore. The following is an extract from his case sheet showing the dosage employed :-

Connaught Hospital, Aldershot.

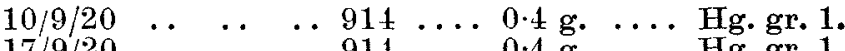

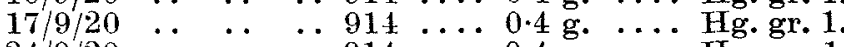

$$
\begin{aligned}
& 24 / 9 / 20 \quad \ldots \quad \ldots \quad \ldots 914 \ldots .049 \text { g. .... Hg. gr. } 1 \\
& 1 / 10 / 20 \ldots-\ldots-\ldots-\ldots . \quad \ldots \text { Hg. gr. } 1
\end{aligned}
$$

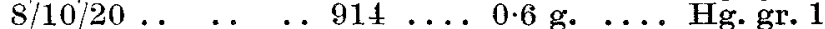

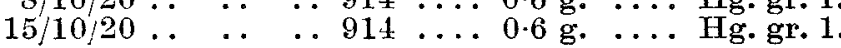

$$
\begin{aligned}
& \text { Rochester Row. }
\end{aligned}
$$

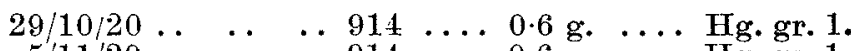

$$
\begin{aligned}
& 5 / 11 / 20 \ldots \ldots \quad \ldots 914 \ldots 0.6 \text { g. } \ldots . . \text { Hg. gr. } 1
\end{aligned}
$$

He reported sick with jaundice, but no other symptoms on Feb. 6th, 1921, and was admitted to the Cambridge Hospital, Aldershot, on that day. So-called catarrhal jaundice is common in the command, and his case presented no peculiarity until the $22 \mathrm{nd}$, when he became depressed and refused food; vomiting set in, the jaundice deepened, and he died comatose in 36 hours. The urine on the day of death contained albumin, blood, and bile-stained granular casts. It showed the presence of arsenic by Marsh's test. Leucin and tyrosin were absent. Post mortem, the live weighed $30 \frac{1}{2} \mathrm{oz}$, and showed the typical appearance of acute yellow atrophy both macroscopically and microscopically. The kidneys showed acute diffuse nephritis and there was some venous congestion of the spleen. The other organs were apparently healthy. No spirochætes were found in films of juice from liver and kidney.

Analysis by Major Elliot, B.Sc., F.C.S., gave the following result :-

$$
\begin{aligned}
& \text { Kidneys Weight in grammes. As. per } 100 \mathrm{~g} \text {. } \\
& \begin{array}{llllllll} 
& \ldots & \ldots & 391 & \ldots & \ldots & 0.02 \mathrm{mg}
\end{array}
\end{aligned}
$$

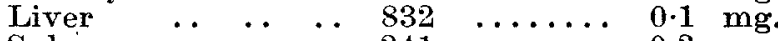

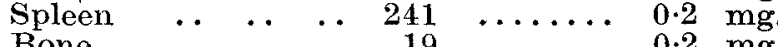

Mr. A. G. R. Foulerton tells me that the relative amounts (if the liver and kidneys are considered together) agree closely with his findings in experimental $\mathrm{As}_{2} \mathrm{O}_{3}$ poisoning. A rough estimate shows that probably nearly one-tenth of the total arsenic administered remained in the body at death. The elimination of arsenic from organic combinations is, I find, a longer process than is usually believed. Three patients free from symptoms were found recently to have arsenic in the urine in demonstrable quantity 11 weeks after their last injection of neo-salvarsan.

I have not been able to find any other record of analysis of the arsenic concentration in so remote a fatality as the above, for permission to publish the details of which $\mathrm{I}$ am indebted to Lieut.-Col. H. C. R. Hine, commanding the Cambridge Hospital.

MEdical GolfIng SocIeTy. - This society has been carried on in a more or less informal manner for 23 years, but it has now been decided to put it on a business footing. Two tournament meetings are to be held annually, and team matches and other competitions for four cups, including two challenge cups, will be arranged. Membership, without election, is open to any gentleman on the Medical Register, on payment of the annual subscription of 10s. to the hon. secretary and treasurer, Dr. Rolf Creasy, jun., 36 , Weymouth-street, London, W. 1. 